\title{
Toll-Like Receptors and Mannose Binding Lectin Gene Polymorphisms Associated with Cryptosporidial Diarrhea in Children in Southern India
}

\author{
Farzana Begum Liakath, ${ }^{1}$ Savitha Varatharajan, ${ }^{1}$ Prasanna Samuel Premkumar, ${ }^{1}$ Chanduni Syed, ${ }^{1}$ Honorine Ward, ${ }^{2}$ \\ Gagandeep Kang, ${ }^{1}$ and Sitara S. R. Ajjampur ${ }^{1 *}$ \\ ${ }^{1}$ The Wellcome Trust Research Laboratory, Division of Gastrointestinal Sciences, Christian Medical College, Vellore, India; ${ }^{2}$ Division of \\ Geographic Medicine and Infectious Diseases, Tufts Medical Center, Boston, Massachusetts
}

\begin{abstract}
In low-resource settings, Cryptosporidium spp. is a common cause of diarrheal disease in children under the age of 3 years. In addition to diarrhea, these children also experience subclinical episodes that have been shown to affect growth and cognitive function. In this study, we screened polymorphisms in the promoter and exon1 regions of the mannose binding lectin 2 (MBL2) gene, as well as single nucleotide polymorphisms (SNPS) described in toll-like receptors (TLR) TLR1, TLR2, TLR4, and TLR9 and TIR domain-containing adaptor protein (TIRAP) genes among children with cryptosporidial diarrhea (cases) and children who only experienced asymptomatic (subclinical) cryptosporidiosis (controls). Among the polymorphisms screened, the variant allele B at codon 54 (rs1800450) of the MBL2 gene was associated with susceptibility to cryptosporidial diarrhea (odds ratio $[\mathrm{OR}]=2.2,95 \%$ confidence interval $[\mathrm{Cl}] 1.1-4.5$ ). When plasma $\mathrm{MBL}$ levels were compared, $72 \%$ of cases were found to be deficient compared with $32 \%$ among controls $(O R=5.09)$. Among TLR polymorphisms screened, multivariate analysis showed that heterozygous genotypes of TLR4 896A/G (rs4986790, OR = 0.33, 95\% Cl: 0.11-0.98) and TIRAP $539 \mathrm{C} / \mathrm{T}$ (rs8177374, OR =0.19, 95\% Cl: 0.06-0.64) SNPs were associated with protection from cryptosporidial diarrhea. Although not statistically significant, these findings suggest that polymorphisms of MBL2 and TLR genes influence susceptibility to symptomatic cryptosporidial diarrhea even in settings with high exposure levels. Further studies to validate these findings in a larger cohort and to understand the role of these polymorphisms in mediating innate and adaptive immune responses to cryptosporidial infection are necessary.
\end{abstract}

\section{INTRODUCTION}

Diarrhea is the second leading cause of morbidity and mortality in children under the age of 5 years in low- to middleincome countries. ${ }^{1}$ The Global Enteric Multi-Center Study and Malnutrition and Enteric Diseases studies as well as the Global Burden of Diseases estimates have identified Cryptosporidium spp. as one of the commonest causes of diarrhea in children under 5 years of age in low- to middle-income countries. ${ }^{2-4}$ Cryptosporidium-associated diarrhea alone accounts for more than 48,000 deaths and more than 4.2 million disability-adjusted life years lost per year. ${ }^{3}$ Children in countries such as Bangladesh, Peru, Malawi, Israel, and India also experience multiple episodes of subclinical or asymptomatic cryptosporidial infections that have been associated with malnutrition, stunting, and cognitive deficits., ${ }^{5,6}$ Birth cohort studies have shown that children in low-resource settings such as urban slums in the Indian subcontinent are exposed to Cryptosporidium spp. by age 3 years (97\% in Vellore, Tamil Nadu, and $77 \%$ in Mirpur, Bangladesh), experiencing either diarrheal or subclinical episodes. ${ }^{7,8}$ The heterogeneity in symptoms and why some children tend to experience overt diarrhea and others only subclinical infections in the same living conditions remain largely unknown. This could be either due to parasite genotype or host susceptibility. Multiple infections (both symptomatic and subclinical) tend to cluster, with children with more than two or three episodes having an increased likelihood of being reinfected, suggesting a genetic predisposition to infection. ${ }^{7}$

The mannose binding lectin 2 (MBL2) gene encodes for a calcium-dependent plasma lectin that has been shown to

*Address correspondence to Sitara S. R. Ajjampur, The Wellcome Trust Research Laboratory, Division of Gastrointestinal Sciences, Christian Medical College, Vellore, India 632004, India. E-mail: sitararao@cmcvellore.ac.in play an important role in innate immune response to various infectious diseases. Low serum MBL levels $(<70 \mathrm{ng} / \mathrm{mL})$ have been associated with cryptosporidial diarrhea in Haitian children. ${ }^{9}$ Carmolli et al. showed that children in Bangladesh who experienced both single and multiple episodes of cryptosporidial diarrhea were more likely to be MBL deficient ( $<500 \mathrm{ng} / \mathrm{mL}$, odds ratio $[\mathrm{OR}]=4.1$ and 7.5 , respectively) compared with children who had no symptomatic infections. They also found that a single nucleotide polymorphism (SNP) in the promoter region of the MBL2 gene $(-221$, rs7096206) was associated with susceptibility to cryptosporidial diarrhea (OR 4.0). ${ }^{10}$ Apart from MBL2 polymorphisms, SNPs of toll-like receptor (TLR) family and signaling adaptor proteins have been shown to influence susceptibility to a variety of infectious diseases. ${ }^{11}$ These SNPs have also been described in the Indian population and are associated with susceptibility to tuberculosis, Helicobacter pylori and hepatitis C virus. ${ }^{12-15}$ Polymorphisms in the TIR domaincontaining adaptor protein gene (TIRAP) required for TLR signaling ${ }^{16}$ have been associated with protection from tuberculosis $^{17}$ and increased risk of malaria ${ }^{18}$ in Indians. Studies in cell culture and animal models suggest a role for TLR2 and TLR4 in early response to cryptosporidial infections. In cholangiocyte cell cultures, infection with Cryptosporidium resulted in selective recruitment of TLR2 and TLR4 with the production of IL8 and IL6 via the MyD88 pathway. ${ }^{19}$ TLR4 expression was also found to be regulated by parasite miRNA (let-7i). MyD88-deficient mice, interferon- $\gamma$ knockout mice, and TLR4 knockout mice have all been shown not to clear cryptosporidial infections. ${ }^{20}$ However, to date, no studies have explored the role of TLR polymorphisms in susceptibility to cryptosporidial infections. In the present study, we sought to determine the association of TLR and MBL polymorphisms as well as plasma MBL levels with cryptosporidial diarrhea in children residing in a periurban slum area in southern India. 


\section{METHODS}

In a previous study, children enrolled in a birth cohort on rotaviral diarrhea (CRI birth cohort) were followed up for all diarrheal episodes from birth until age 3 years between 2002 and 2006 in a semiurban slum in Vellore, southern India. ${ }^{21}$ In this study, comparison of MBL and TLR polymorphisms among cases defined as children in the birth cohort who experienced cryptosporidial diarrhea under the age of 2 years $^{22}$ and controls defined as children in the birth cohort who only experienced asymptomatic (subclinical) cryptosporidiosis under the age of 2 years ${ }^{23}$ was carried out. Among the 452 children followed up in the birth cohort, 39 children were identified as having cryptosporidial diarrhea and were categorized as cases and 96 children who did not experience any cryptosporidial diarrhea who were younger than age 2 years (ascertained by SSU rRNA PCR for Cryptosporidium spp. carried out on all diarrheal samples) were categorized as controls. Blood samples were collected from 36 of 39 cases and 82 of 96 controls, DNA was extracted with the QIAamp DNA blood mini kit (Qiagen Inc., Valencia, CA), and SNPs were genotyped using previously described methods (Supplemental Table 1). ${ }^{37-41}$ Promoter diplotypes for $M B L 2$ were classified as described previously as LY/LX, HY/LY, LY/LY, LX/LX, HY/LX, and $\mathrm{HY} / \mathrm{HY}{ }^{24}$ Haplotype frequencies for MBL2, TLR4, and TLR9 were calculated based on the expectation-maximization algorithm using Haploview 4.1 and those with frequencies $>$ $2 \%$ were compared. Hardy-Weinberg equilibrium was tested using the GENHWCCI function in STATA 11.0 (StataCorp, College Station, TX). Plasma levels of functional MBL were measured by ELISA using the Human MBL ELISA test kit (HyCult Biotechnology). The samples were tested at a 1:20 dilution, and MBL levels were estimated by interpolated values with linear standard curves as per the kit protocol.

Distribution of baseline characteristics and frequencies of SNPs were compared between cases and controls using either $\chi^{2}$ tests or Fisher's exact tests, as appropriate. Association of SNPs were evaluated using ORs and 95\% confidence intervals (Cls), and analyses were adjusted for birth weight and number of diarrheal episodes by logistic regression to produce adjusted ORs. $P$ values were adjusted ( $p$ adj) for multiple comparison using the Benjamin-Hochberg adjustment. A receiver operating characteristic curve (ROC) analysis was used to determine the appropriate cutoff to define plasma MBL deficiency in this population and assess the association with MBL2 promoter diplotypes. The study protocol was approved by the Institutional Review Board of the Christian Medical College, Vellore, and written informed consent was obtained from parents of all children enrolled in this study.

\section{RESULTS}

Comparison of baseline characteristics showed that more controls had low birth weight compared with cases $(P<$ 0.05 ) and cases had diarrhea more frequently (five to nine episodes) than controls (one to three episodes; $P<0.001$ ) (Supplemental Table 2). ${ }^{42}$ Hence, the multivariate logistic regression analysis performed to determine the association of SNP was adjusted for birth weight and the number of diarrheal episodes. Among the MBL2 exon1 polymorphisms, the variant allele B at codon 54 ( $r$ 1800450) was found to be associated with susceptibility to cryptosporidial diarrhea $(\mathrm{OR}=2.2,95 \% \mathrm{Cl}: 1.1-4.5)$ (Table 1) in the multivariate analysis, whereas variant allele $\mathrm{C}$ at codon 57 (rs1800451) did not show any association ( $\mathrm{OR}=0.4,95 \% \mathrm{Cl}$ : 0.1-1.6). Among MBL2 haplotypes with a frequency $>2 \%$, the HXBA haplotype was found to be associated with risk of cryptosporidial diarrhea $(\mathrm{OR}=6.5,95 \% \mathrm{Cl}$ : 1.0-41.3) (Table 2). However, when adjusted for multiple comparisons ( $p$-adj), the MBL2 rs1800450 polymorphism and HXBA haplotype association with cryptosporidial diarrhea was not significant. Plasma MBL levels ranged from 63.6 to $3823.2 \mathrm{ng} / \mathrm{mL}$. The median age of children at which the MBL levels were measured was 5.91 years (range 5.3-6.7 years). Cases had significantly lower MBL levels (median $575.6 \mathrm{ng} / \mathrm{mL}$, interquartile range [IQR] $420.3-883.2 \mathrm{ng} / \mathrm{mL}$ ) than controls (median $1090.9 \mathrm{ng} / \mathrm{mL}$, IQR $770-1824.7 \mathrm{ng} / \mathrm{mL} ; P<0.001$ ) (Figure 1A). When plasma MBL levels among the controls for each promoter diplotype were compared, the LY/LX diplotype had markedly lower levels $(P=0.018)$ and was chosen to represent the "deficient" diplotype in this population. Receiver operating characteristic curve generated with plasma MBL levels in the "deficient" controls with the LY/LX diplotype showed that a cutoff of $873.5 \mathrm{ng} / \mathrm{mL}$ would be optimal (sensitivity $81 \%$, specificity $77 \%$, area under the curve $=0.83$ ) (Figure 1B). When this cutoff was then reapplied to the diplotype distribution, all children (cases and controls) with the LY/LX genotype were classified as "deficient," thereby validating the cutoff (Figure 1C). Using this cutoff, when the proportion of children with MBL deficiency among cases and controls was compared, more than twice the number of cases $(72 \%)$ than controls (32\%) were found to be deficient (OR $=5.09$ ) (Figure 1C).

When TLR polymorphisms were examined, the minor allele frequency (MAF) of the TLR1 SNP rs5743618 was similar in cases and controls (Table 1), and all subjects enrolled in this study had the ancestral allele at the TLR2 SNP rs5743708 locus, consequently neither of these SNPs was analyzed further. The TLR4 SNP rs4986790 heterozygous genotype $896 \mathrm{~A} / \mathrm{G}$ and the TIRAP SNP rs8177374 heterozygous 539C/ $T$ genotypes were seen more often among controls than cases. Both SNP were associated with protection from cryptosporidial diarrhea in the multivariate analysis $(\mathrm{OR}=0.33$, 95\% Cl: $0.11-0.98$, and $\mathrm{OR}=0.19,95 \% \mathrm{Cl}: 0.06-0.64$, respectively) (Table 1) but only the TIRAP SNP approached significance $(p-a d j=0.08)$. None of the other polymorphisms showed any significant association with cryptosporidial diarrhea. When haplotype analysis was carried out, no significant association for either TLR4 or TLR9 haplotypes was seen with the risk of cryptosporidial diarrhea (Table 2).

\section{DISCUSSION}

Cryptosporidiosis remains an important cause of diarrheal disease and stunting in children in low-resource settings. In this study, genetic susceptibility to cryptosporidial diarrhea in an urban slum with poor sanitation and high levels of exposure was explored. Increased susceptibility to cryptosporidial diarrhea among those with plasma or serum MBL deficiency has been shown in Bangladeshi and Haitian children. ${ }^{9,25}$ Increased risk of cryptosporidial diarrhea has also been associated with MBL2 polymorphisms in both the exon 
TABLE 1

Univariate and multivariate analysis of the association between TLR, TIRAP, and MBL2 SNPs and cryptosporidial diarrhea

\begin{tabular}{|c|c|c|c|c|c|c|c|c|c|c|c|c|c|}
\hline \multirow[b]{2}{*}{ SNP } & \multicolumn{2}{|c|}{ MAF \% } & \multicolumn{3}{|c|}{ Univariate } & \multicolumn{4}{|c|}{$\begin{array}{l}\text { Multivariate adjusted } \\
\text { only for birth weight }\end{array}$} & \multicolumn{4}{|c|}{$\begin{array}{l}\text { Multivariate adjusted for birth weight } \\
\text { and number of diarrheal episodes }\end{array}$} \\
\hline & $\begin{array}{l}\text { Cases, } \\
n=36\end{array}$ & $\begin{array}{c}\text { Controls, } \\
n=82\end{array}$ & OR & $95 \% \mathrm{Cl}$ & $P$ value & OR & $95 \% \mathrm{Cl}$ & $P$ value & p-adj* ${ }^{*}$ & OR & $95 \% \mathrm{Cl}$ & $P$ value & $p-\operatorname{adj}^{*}$ \\
\hline $\begin{array}{l}\text { TLR4 } \\
\text { rs4986790 } \\
\text { 896A/G } \\
\text { Asp299Gly }\end{array}$ & 11 & 23 & 0.38 & $0.16-0.90$ & 0.08 & 0.31 & $0.12-0.76$ & 0.01 & 0.04 & 0.33 & $0.11-0.98$ & 0.04 & 0.16 \\
\hline $\begin{array}{l}\text { TLR4 } \\
\text { rs4986791 } \\
1196 \mathrm{C} / \mathrm{T} \\
\text { Thr399lle }\end{array}$ & 11 & 18 & 0.54 & $0.22-1.31$ & 0.38 & 0.44 & $0.18-1.09$ & 0.08 & 0.22 & 0.45 & $0.15-1.37$ & 0.13 & 0.36 \\
\hline $\begin{array}{l}\text { TIRAP } \\
\text { rs8177374 } \\
\text { 539C/T } \\
\text { Ser180Leu }\end{array}$ & 11 & 32 & 0.17 & $0.08-0.43$ & 0.001 & 0.17 & $0.07-0.44$ & 0.001 & 0.01 & 0.19 & $0.06-0.64$ & 0.007 & 0.08 \\
\hline $\begin{array}{l}\text { TLR1 } \\
\text { rs5743618 } \\
\text { 1805 T/G } \\
\text { lle602Ser }\end{array}$ & 4 & 4 & 0.97 & $0.24-4.00$ & 0.97 & 0.82 & $0.20-3.39$ & 0.79 & 0.87 & 0.61 & $0.09-3.98$ & 0.61 & 0.61 \\
\hline $\begin{array}{l}\text { TLR9 } \\
\text { rs5743836 } \\
\text { C-1237T }\end{array}$ & 83 & 92 & 2.32 & $0.88-6.14$ & 0.22 & 2.13 & $0.78-5.83$ & 0.14 & 0.26 & 2.13 & $0.57-8.01$ & 0.14 & 0.31 \\
\hline $\begin{array}{l}\text { TLR9 } \\
\text { rs } 1870884 \\
\text { T-1486C }\end{array}$ & 43 & 43 & 0.96 & $0.31-2.99$ & 0.95 & 0.96 & $0.30-3.07$ & 0.95 & 0.95 & 0.47 & $0.09-2.39$ & 0.37 & 0.45 \\
\hline $\begin{array}{l}\text { TLR2 } \\
\text { (-196 to }-174) \\
\text { (del) }\end{array}$ & 33 & 39 & 0.86 & $0.44-1.70$ & 0.79 & 0.85 & $0.43-1.69$ & 0.65 & 0.79 & 1.94 & $0.71-5.23$ & 0.19 & 0.35 \\
\hline $\begin{array}{l}M B L 2 \\
\quad r s 11003125 \\
\text { G-550C } \\
\quad H>L\end{array}$ & 73 & 60 & 1.68 & $0.95-2.97$ & 0.19 & 1.58 & $0.88-2.83$ & 0.12 & 0.26 & 1.66 & $0.73-3.74$ & 0.22 & 0.30 \\
\hline $\begin{array}{l}M B L 2 \\
\quad r s 7096206 \\
\text { C-221G } \\
Y>X\end{array}$ & 33 & 27 & 1.26 & $0.74-2.17$ & 0.59 & 1.17 & $0.66-2.07$ & 0.58 & 0.79 & 0.80 & $0.54-3.62$ & 0.48 & 0.53 \\
\hline $\begin{array}{l}\text { MBL2 } \\
\text { rs1800450 } \\
\text { 230G/A } \\
\text { Gly54Asp } \\
\text { A }>B\end{array}$ & 54 & 34 & 1.78 & $1.09-2.79$ & 0.04 & 1.96 & $1.18-3.24$ & 0.009 & 0.04 & 2.20 & $1.08-4.51$ & 0.03 & 0.17 \\
\hline $\begin{array}{l}\text { MBL2 } \\
\text { rs1800451 } \\
239 \text { G/A } \\
\text { Gly57Glu } \\
\text { A }>\text { C }\end{array}$ & 5 & 12 & 0.47 & $0.16-1.35$ & $0.15^{\star}$ & 0.47 & $0.16-1.35$ & 0.16 & 0.25 & 0.43 & $0.11-1.61$ & 0.21 & 0.32 \\
\hline
\end{tabular}

TABLE 2

Haplotype frequency of SNPs in TLR4, TLR9, and MBL2 among children with and without cryptosporidial diarrhea

\begin{tabular}{|c|c|c|c|c|c|c|c|c|}
\hline $\begin{array}{c}\text { TLR4 } \\
\text { rs4986790 } \\
896 \mathrm{~A} / \mathrm{G}\end{array}$ & $\begin{array}{l}\text { TLR4 } \\
\mathrm{rs} 4986791 \\
1196 \mathrm{C} / \mathrm{T}\end{array}$ & $\begin{array}{l}T L R 9 \\
\text { rs5743836 } \\
(-1237)\end{array}$ & $\begin{array}{l}\text { TLR9 } \\
\text { rs1870884 } \\
(-1486)\end{array}$ & Controls & Cases & OR $(95 \% \mathrm{Cl})$ & $P$ value & $\mathrm{p}$-adj \\
\hline $\bar{G}$ & $\mathrm{C}$ & $\mathrm{C}$ & $T$ & 0.36 & 0.54 & 1.00 & - & \\
\hline G & C & C & C & 0.23 & 0.26 & $1.03(0.29-3.68)$ & 0.96 & 0.96 \\
\hline A & $\mathrm{T}$ & C & $\mathrm{T}$ & 0.09 & 0.00 & $0.50(0.12-2.03)$ & 0.33 & 0.59 \\
\hline G & C & $\mathrm{T}$ & C & 0.10 & 0.06 & $0.58(0.10-3.30)$ & 0.54 & 0.61 \\
\hline A & C & C & $\mathrm{T}$ & 0.07 & 0.00 & $0.27(0.05-1.37)$ & 0.12 & 0.54 \\
\hline G & $\mathrm{T}$ & C & $\mathrm{T}$ & 0.02 & 0.03 & $0.03(0.06-1.55)$ & 0.15 & 0.45 \\
\hline $\begin{array}{l}\text { MBL2 } \\
\quad \text { rs11003125 } \\
(-550)\end{array}$ & $\begin{array}{c}M B L 2 \text { rs7096206 } \\
(-221)\end{array}$ & $\begin{array}{c}\text { MBL2 } \\
\text { rs1800450 } \\
\text { codon } 54\end{array}$ & $\begin{array}{c}M B L 2 \\
\text { rs1800451 } \\
\text { codon } 57\end{array}$ & & & & & \\
\hline$C(L)$ & $C(X)$ & $G(A)$ & $G(A)$ & 0.26 & 0.08 & 1.00 & - & \\
\hline$G(H)$ & $C(X)$ & $G(A)$ & $G(A)$ & 0.19 & 0.17 & $2.47(0.40-15.45)$ & 0.34 & 0.51 \\
\hline$G(H)$ & $\mathrm{G}(\mathrm{Y})$ & $G(A)$ & $G(A)$ & 0.17 & 0.21 & $1.78(0.38-8.34)$ & 0.47 & 0.60 \\
\hline$G(H)$ & $C(X)$ & $A(B)$ & $G(A)$ & 0.15 & 0.08 & $6.50(1.02-41.27)$ & 0.05 & 0.45 \\
\hline$C(L)$ & $C(X)$ & $A(B)$ & $G(A)$ & 0.13 & 0.14 & $2.68(0.49-14.65)$ & 0.26 & 0.59 \\
\hline
\end{tabular}


A

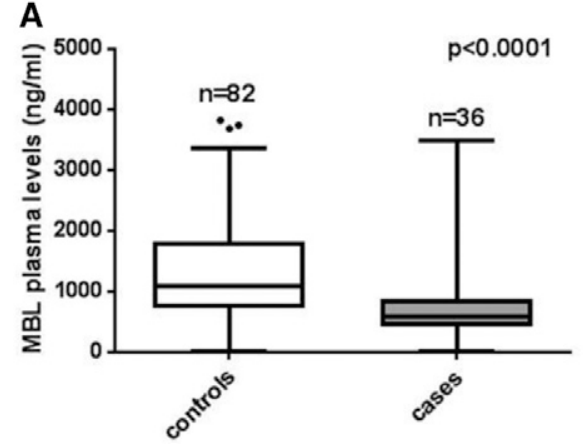

$\mathrm{C}$

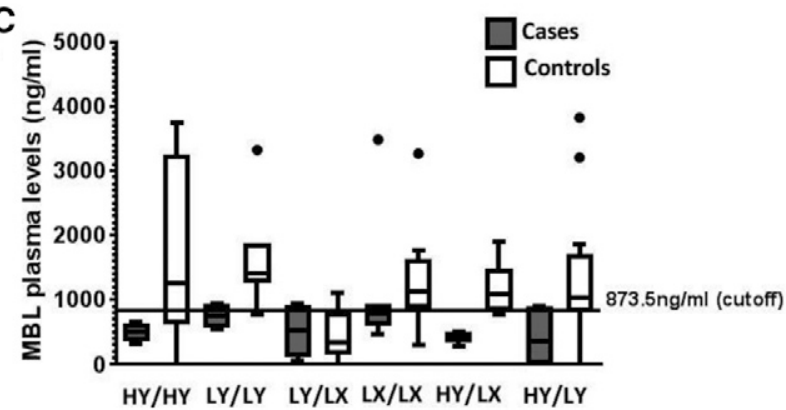

B

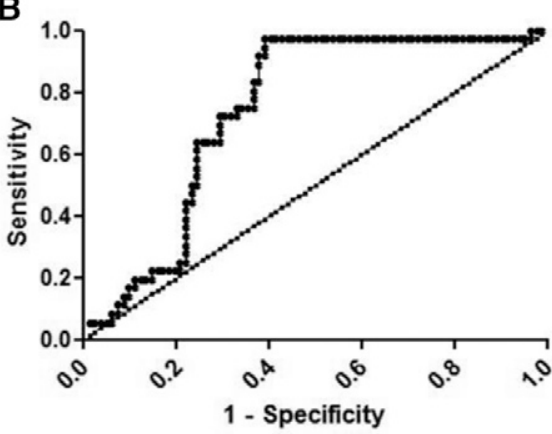

Figure 1. Plasma mannose binding lectin (MBL) levels in cryptosporidial cases and controls. (A) MBL levels between cases and controls. (B) Receiver operating characteristic analysis of MBL levels in controls to determine an optimal cutoff. (C) Comparison of MBL levels among the $M B L 2$ promoter diplotypes in cases and controls.

1 region ${ }^{25,26}$ as well as the promoter region. ${ }^{25}$ Our study has further validated these findings in children in southern India. Plasma MBL2 deficiency and a SNP in the MBL2 gene in the exon 1 region (codon 54) were associated with risk of cryptosporidial diarrhea. Because the samples collected were not temporally related to the episode of diarrhea, the levels of $\mathrm{MBL}$ estimated were not related to acute response but more reflective of baseline levels. Furthermore, the MBL2 diplotype associated with low plasma MBL in the southern Indian population (LY/LX) was identified and a more appropriate cutoff to determine MBL deficiency was determined.

This is the first study to indicate an association between TLR4 and TIRAP polymorphisms with cryptosporidiosis. Presence of the rs 4986790 polymorphism in TLR4 has been found to have a protective effect in other intracellular pathogens as well, including Mycobacterium lepra ${ }^{27}$ and Legionella. ${ }^{28}$ In a more recent study by Ortega et al., the minor allele $\mathrm{G}$ was also associated with deceased risk of active tuberculosis $(\mathrm{OR}=0.31) .{ }^{29} \mathrm{~A}$ meta-analysis of genetic susceptibility studies showed an increased odds of parasitic infections associated with this SNP, but none of the studies included in the analysis involved Cryptosporidium or any other gastrointestinal parasite. ${ }^{30}$ The TIRAP gene encodes an adaptor protein that is essential for downstream signaling of $T L R 2$ and TLR4. ${ }^{31}$ The nonsynonymous polymorphism in TIRAP SNP rs8177374 leads to altered binding of TIRAP to MyD88. ${ }^{32} \mathrm{Sim}-$ ilar to the findings of this study, the TIRAP SNP has been associated with protection from invasive pneumococcal disease, bacteremia, malaria, and tuberculosis. ${ }^{33}$ The potential protective effect of these SNPs in cryptosporidial diarrhea could be due to decreased activation of downstream signaling pathways that lead to intestinal inflammation. Increased levels of inflammatory markers (including cytokines) have been found in stools of children with cryptosporidial diarrhea. ${ }^{34}$ These SNPs could also affect TLR mediation of adaptive immune response to cryptosporidiosis. Further mechanistic studies are required to determine the role of these SNP and whether they could serve as potential therapeutic targets.

In addition to MBL and TLR SNPs, SNPs in other genes have been shown to affect risk of cryptosporidial infections. The HLA class II DQB1 ${ }^{*} 0301$ allele was found to provide protective effect in Bangladesh children compared with symptomatic infection. ${ }^{35}$ More recently an intronic SNP (rs58296998) in the protein kinase $\mathrm{C}$ gene (PRKCA) identified by a genomewide association study was found to be associated with higher risk of cryptosporidiosis in the first year of life among 873 children in Bangladesh. ${ }^{36}$ The authors in this study used samples collected from multiple, independent cohorts in Bangladesh to determine genetic susceptibility. A similar approach with samples from larger, well-characterized cohorts of children from the same genetic background are warranted to validate the findings of the present study. In conclusion, we have validated the association between MBL deficiency and increased risk of cryptosporidial diarrhea and identified SNPs, in MBL2, TLR4, and in TIRAP genes that may confer protection from developing diarrhea during a cryptosporidial infection.

Received June 8, 2020. Accepted for publication July 17, 2021.

Published online September 27, 2021.

Note: Supplemental tables appear at www.ajtmh.org.

Acknowledgments: We thank all the children and parents who participated in this study and the field workers and technical staff who helped with sample collection and processing.

Funding support: This work was supported by the Indian Council for Medical Research grant (Immu.19/11/8/2008ECD-I) to S. S. R. A., National Institutes of Health (R03 TW07211) to H. W., and Wellcome 
Trust, UK (063144) to G. K. F. B. was supported by a fellowship grant from the Lady Tata Memorial Trust, India.

Authors' addresses: Farzana Begum Liakath, Savitha Varatharajan, Chanduni Syed, Gagandeep Kang, and Sitara S. R. Ajjampur, The Wellcome Trust Research Laboratory, Division of Gastrointestinal Sciences, Christian Medical College, Vellore, Indian, E-mails: farzana. liakath@gmail.com, savitha0384@gmail.com, syedchanduni@gmail. com, gkang@cmcvellore.ac.in, and sitararao@cmcvellore.ac.in. Prasanna Samuel Premkumar, Department of Biostatistics, Christian Medical College, Vellore, India, E-mail: prasanna.samuel@cmcvellore. ac.in. Honorine Ward, Division of Geographic Medicine and Infectious Diseases, Tufts University School of Medicine, Boston, MA, E-mail: hward@tuftsmedicalcenter.org.

This is an open-access article distributed under the terms of the Creative Commons Attribution (CC-BY) License, which permits unrestricted use, distribution, and reproduction in any medium, provided the original author and source are credited.

\section{REFERENCES}

1. Levine MM et al., 2020. Diarrhoeal disease and subsequent risk of death in infants and children residing in low-income and middle-income countries: analysis of the GEMS case-control study and 12-month GEMS-1A follow-on study. Lancet Glob Health 8: e204-e214.

2. Delahoy MJ et al., 2018. Clinical, environmental, and behavioral characteristics associated with Cryptosporidium infection among children with moderate-to-severe diarrhea in rural western Kenya, 2008-2012: the Global Enteric Multicenter Study (GEMS). PLoS Negl Trop Dis 12: e0006640.

3. Khalil IA et al., 2018. Morbidity, mortality, and long-term consequences associated with diarrhoea from Cryptosporidium infection in children younger than 5 years: a meta-analyses study. Lancet Glob Health 6: e758-e768.

4. Korpe PS et al., 2018. Epidemiology and risk factors for cryptosporidiosis in children from 8 low-income sites: results from the MAL-ED study. Clin Infect Dis Off Publ Infect Dis Soc Am 67: 1660-1669.

5. Guerrant RL, DeBoer MD, Moore SR, Scharf RJ, Lima AAM, 2013. The impoverished gut-a triple burden of diarrhoea, stunting and chronic disease. Nat Rev Gastroenterol Hepatol 10: $220-229$.

6. Platts-Mills JA et al., 2015. Pathogen-specific burdens of community diarrhoea in developing countries: a multisite birth cohort study (MAL-ED). Lancet Glob Health 3: e564-e575.

7. Kattula D et al., 2017. Natural history of cryptosporidiosis in a birth cohort in southern India. Clin Infect Dis Off Publ Infect Dis Soc Am 64: 347-354.

8. Korpe PS et al., 2016. Natural history of cryptosporidiosis in a longitudinal study of slum-dwelling Bangladeshi children: association with severe malnutrition. PLoS Negl Trop Dis 10: e0004564.

9. Kirkpatrick BD et al., 2006. Serum mannose-binding lectin deficiency is associated with cryptosporidiosis in young Haitian children. Clin Infect Dis Off Publ Infect Dis Soc Am 43: 289-294.

10. Carmolli $\mathrm{M}$ et al., 2009. Deficient serum mannose-binding lectin levels and MBL2 polymorphisms increase the risk of single and recurrent Cryptosporidium infections in young children. $J$ Infect Dis 200: 1540-1547.

11. Skevaki C, Pararas M, Kostelidou K, Tsakris A, Routsias JG, 2015. Single nucleotide polymorphisms of Toll-like receptors and susceptibility to infectious diseases. Clin Exp Immunol 180: $165-177$.

12. Loganathan R, Nazeer M, Goda V, Devaraju P, Ali M, Karunakaran P, Jayaraman M, 2017. Genetic variants of TLR4 and TLR9 are risk factors for chronic Helicobacter pylori infection in South Indian Tamils. Hum Immunol 78: 216-220.

13. Medhi S, Deka M, Deka P, Swargiary SS, Hazam RK, Sharma MP, Gumma PK, Asim M, Kar P, 2011. Promoter region polymorphism and expression profile of toll like receptor-3 (TLR-3) gene in chronic hepatitis C virus (HCV) patients from India. Indian J Med Res 134: 200-207.
14. Mittal M, Biswas SK, Singh V, Arela N, Katoch VM, Das R, Yadav VS, Bajaj B, Mohanty KK, 2018. Association of Toll like receptor 2 and 9 gene variants with pulmonary tuberculosis: exploration in a northern Indian population. Mol Biol Rep 45: 469-476.

15. Selvaraj $P$, Harishankar M, Singh B, Jawahar MS, Banurekha VV, 2010. Toll-like receptor and TIRAP gene polymorphisms in pulmonary tuberculosis patients of South India. Tuberculosis (Edinb) 90: 306-310.

16. Horng T, Barton GM, Flavell RA, Medzhitov R, 2002. The adaptor molecule TIRAP provides signaling specificity for Toll-like receptors. Nature 420: 329-333.

17. Saranathan R et al., 2020. MAL adaptor (TIRAP) S180L polymorphism and severity of disease among tuberculosis patients. Infect Genet Evol J Mol Epidemiol Evol Genet Infect Dis 77: 104093.

18. Panda AK et al., 2016. Heterozygous mutants of TIRAP (S180L) polymorphism protect adult patients with Plasmodium falciparum infection against severe disease and mortality. Infect Genet Evol J Mol Epidemiol Evol Genet Infect Dis 43: $146-150$.

19. Chen X-M, O'Hara SP, Nelson JB, Splinter PL, Small AJ, Tietz PS, Limper AH, LaRusso NF, 2005. Multiple TLRs are expressed in human cholangiocytes and mediate host epithelial defense responses to Cryptosporidium parvum via activation of NF-kappaB. J Immunol Baltim Md 175: 7447-7456.

20. O'Hara SP, Bogert PST, Trussoni CE, Chen X, LaRusso NF, 2011. TLR4 promotes Cryptosporidium parvum clearance in a mouse model of biliary cryptosporidiosis. J Parasitol 97: 813-821.

21. Gladstone BP et al., 2008. Infant morbidity in an Indian slum birth cohort. Arch Dis Child 93: 479-484.

22. Ajjampur SSR, Gladstone BP, Selvapandian D, Muliyil JP, Ward H, Kang G, 2007. Molecular and spatial epidemiology of cryptosporidiosis in children in a semiurban community in South India. J Clin Microbiol 45: 915-920.

23. Sarkar R, Aijampur SSR, Muliyil J, Ward H, Naumova EN, Kang $\mathrm{G}, 2012$. Serum IgG responses and seroconversion patterns to Cryptosporidium gp15 among children in a birth cohort in south India. Clin Vaccine Immunol 19: 849-854.

24. Steffensen R, Thiel S, Varming K, Jersild C, Jensenius JC, 2000. Detection of structural gene mutations and promoter polymorphisms in the mannan-binding lectin (MBL) gene by polymerase chain reaction with sequence-specific primers. $J$ Immunol Methods 241: 33-42.

25. Carmolli $M$ et al., 2009. Deficient serum mannose-binding lectin levels and MBL2 polymorphisms increase the risk of single and recurrent Cryptosporidium infections in young children. $J$ Infect Dis 200: 1540-1547.

26. Kelly $P$, Jack DL, Naeem A, Mandanda B, Pollok RC, Klein NJ, Turner MW, Farthing MJ, 2000. Mannose-binding lectin is a component of innate mucosal defense against Cryptosporidium parvum in AIDS. Gastroenterology 119: 1236-1242.

27. Bochud P-Y et al., 2009. Polymorphisms in Toll-like receptor 4 (TLR4) are associated with protection against leprosy. Eur $J$ Clin Microbiol Infect Dis Off Publ Eur Soc Clin Microbiol 28: 1055-1065.

28. Hawn TR, Verbon A, Janer M, Zhao LP, Beutler B, Aderem A, 2005. Toll-like receptor 4 polymorphisms are associated with resistance to Legionnaires' disease. Proc Natl Acad Sci USA 102: 2487-2489.

29. Ortega E, Hernández-Bazán S, Sánchez-Hernández B, LiconaLimón I, Fuentes-Dominguez J, 2020. Single nucleotide polymorphisms in TLR4 affect susceptibility to tuberculosis in Mexican population from the state of Veracruz. $J$ Immunol Res 2020: 2965697.

30. Ziakas PD, Prodromou ML, El Khoury J, Zintzaras E, Mylonakis $E$, 2013. The role of TLR4 $896 \mathrm{~A}>\mathrm{G}$ and $1196 \mathrm{C}>\mathrm{T}$ in susceptibility to infections: a review and meta-analysis of genetic association studies. PLoS One 8: e81047.

31. Yamamoto $\mathrm{M}$ et al., 2002. Essential role for TIRAP in activation of the signalling cascade shared by TLR2 and TLR4. Nature 420: 324-329.

32. Capparelli R, De Chiara F, Di Matteo A, Medaglia C, lannelli D, 2013. The MyD88 rs6853 and TIRAP rs8177374 polymorphic 
sites are associated with resistance to human pulmonary tuberculosis. Genes Immun 14: 504-511.

33. Khor CC et al., 2007. A Mal functional variant is associated with protection against invasive pneumococcal disease, bacteremia, malaria and tuberculosis. Nat Genet 39: 523-528.

34. Pantenburg B, Dann SM, Wang H-C, Robinson P, CastellanosGonzalez A, Lewis DE, White AC, 2008. Intestinal immune response to human Cryptosporidium sp. infection. Infect Immun 76: 23-29.

35. Kirkpatrick BD, Haque R, Duggal P, Mondal D, Larsson C, Peterson K, Akter J, Lockhart L, Khan S, Petri WA, 2008. Association between Cryptosporidium infection and human leukocyte antigen class I and class II alleles. J Infect Dis 197: 474-478.

36. Wojcik GL et al., 2020. Genome-wide association study of cryptosporidiosis in infants implicates PRKCA. MBio 11: e03343-19.

37. Lorenz E, Schwartz DA, Martin PJ, Gooley T, Lin MT, Chien JW, Hansen JA, Clark JG, 2001. Association of TLR4 mutations and the risk for acute GVHD after HLA-matchedsibling hematopoietic stem cell transplantation. Biol Blood Marrow Transplant J Am Soc Blood Marrow Transplant 7: 384-387.
38. Ramasawmy R, Cunha-Neto E, Fae KC, Borba SCP, Teixeira PC, Ferreira SCP, Goldberg AC, lanni B, Mady C, Kalil J, 2009. Heterozygosity for the S180L variant of MAL/TIRAP, a gene expressing an adaptor protein in the Toll-like receptor pathway, is associated with lower risk of developing chronic Chagas cardiomyopathy. $J$ Infect Dis 199: 1838-1845.

39. Pandey S, Mittal RD, Srivastava M, Srivastava K, Singh S, Srivastava S, Mittal B, 2009. Impact of Toll-like receptors [TLR] 2 (-196 to -174 del) and TLR 4 (Asp299Gly, Thr399lle) in cervical cancer susceptibility in North Indian women. Gynecol Oncol 114: 501-505.

40. Ogus AC, Yoldas B, Ozdemir T, Uguz A, Olcen S, Keser I, Coskun M, Cilli A, Yegin O, 2004. The Arg753GLn polymorphism of the human toll-like receptor 2 gene in tuberculosis disease. Eur Respir J 23: 219-223.

41. Steffensen R, Thiel S, Varming K, Jersild C, Jensenius JC, 2000. Detection of structural gene mutations and promoter polymorphisms in the mannan-binding lectin (MBL) gene by polymerase chain reaction with sequence-specific primers. J Immunol Methods 241: 33-42.

42. Gladstone BP et al., 2008. Infant morbidity in an Indian slum birth cohort. Arch Dis Child 93: 479-484. 